\title{
IDENTIFIKASI SERANGGA HAMA DAN TINGKAT KERUSAKAN BIBIT TREMBESI (Samanea saman (Jacq.). Merr. DI AREAL BPDASHL KAPUAS KOTA PONTIANAK
}

\author{
(The Identification of Insect Pests And The Degree of Damage To Trembesi Seeds (Samanea \\ saman (Jacq.). Merr. In The BPDASHL Kapuas District of Pontianak).
}

\author{
Koteng, Rosa Suryantini dan Hj. Ratna Herawatiningsih \\ Fakultas kehutanan Universitas Tanjungpura Jl. Daya Nasional, Pontianak 78124 \\ E-mail: Kotengjr18@Gmail.com
}

\begin{abstract}
Trembesi is a fast growing species and has a high resistance to the environment and can be harvested within a short period of planting rotation of 5-8 years. This type was chosen because it has a unique texture, besides that this tree is believed to be able to contribute to tackling air pollution and the threat of global warming. Trembesi is also a tree that is an alternative that can be cultivated extensively for the purpose of rehabilitating marginal lands. However, the supply of healthy and quality trembesi seeds is still constrained by the presence of destructive pest insects. This study aims to identify pest insects that attack trembesi seedlings and determine the level of damage caused by pest insects by using calculations based on the types of visible damage, in the permanent nursery area of Kapuas City of Pontianak. The method used in this study is the census method with direct observation of trembesi seeds in the nursery. The results of the study stated that there were 5 types of insects which were thought to attack trembesi seeds, in the nursery area there were 5 types which included cone grasshopper (Tagasta marginella), Small grasshopper (Oxya sp.), Woodhopper (Valanga nigricornis). the Hemiptera order includes the walang sangit (Leptocorisa acuta). caterpillar tritip (Plutella sp.), The results showed an average percentage of damage caused by insect pests was $34.02 \%$ and the percentage level of damage was 22,02\% of the total seedlings of 2,880 seeds observed and included in the category of minor damage. Although including the category of minor damage, it is necessary to further improve cleaning in the environment around the nursery area so that it can reduce the potential percentage and damage to the seedlings.
\end{abstract}

Keywords: Identification, insects, level of destruction, pests, trembesi seedlings

\section{PENDAHULUAN}

Saat ini telah terjadi penurunan pasokan kayu sebagai bahan baku industri dari hutan alam yang di sebabkan oleh menurunnya kualitas dan kuantitas hutan alam seiring meningkatnya jumlah penduduk yang diikuti dengan peningkatan kebutuhan akan sandang, pangan dan papan untuk keperluan hidupnya. Karena kuantitas pohon yang ditebang tidak seimbang dengan pohon yang tumbuh mengakibatkan jumlah pohon dalam hutan semakin menurun dan juga dapat berakibat terancamnya kebutuhan manusia akan kayu. Upaya untuk menjamin agar kebutuhan kayu bisa terus terpenuhi secara berkesinambungan, kita tidak dapat hanya tergantung pada pertumbuhan pohon secara alam, harus ada upayaupaya penanaman dan pemeliharaan khususnya terhadap jenis-jenis niagawi atau jenis-jenis yang di minati salah 
satunya adalah trembesi (Mursono. 2015).

Trembesi merupakan jenis pohon cepat tumbuh (fast growing species) sehingga dapat dipanen dalam waktu yang relatif singkat dengan rotasi tanam sekitar 5-8 tahun Jenis ini dipilih sebagai salah satu jenis tanaman hutan tanaman industri di Indonesia, karena mampu beradaptasi pada berbagai jenis tanah, karakteristik silvikulturnya yang bagus serta kualitas kayunya dapat diterima untuk industri kayu pertukangan dan sangat berkontribusi dalam menanggulangi pencemaraan udara dari ancaman pemanasan global (Krisnawati dkk. 2011). trembesi adalah pohon yang menjadi salah satu alternatif yang dapat diusahakan secara ekstensif untuk tujuan rehabilitasi lahan-lahan marginal. Usaha penyediaan bibit yang berkualitas dilakukan dengan mengadakan pembibitan di persemaian. Salah satu lokasi persemaian yang ada di Kota Pontianak adalah persemaian permanen Balai Pengelolaan Daera Aliran Sungai dan Hutan Lindung (BPDASHL) Kapuas Pontianak yang terletak di Jalan Kebangkitan Nasional Kecamatan Pontianak Utara. Tujuan dibangunnya persemaian permanen ini adalah untuk memenuhi kebutuhan bibit yang berkualitas secara berkesinambungan dalam jumlah banyak untuk mencukupi kekurangan bibit dalam rangka penanaman dan mendukung kegiatan rehabilitasi hutan dan lahan.

Pada areal persemaian BPDASHL Kapuas Kota Pontianak dilakukan pembibitan tanamam trembesi dan berbagai jenis tanaman lainnya. Penyediaan bibit trembesi yang sehat dan berkualitas masih terkendala dengan adanya serangan serangga hama perusak yang apabila tidak dikendalikan dapat berpotensi sebagai hama. Serangga hama adalah serangga yang dapat menyebabkan kerusakan pada bagian tanaman. serangga dapat dikatakan sebagai hama apabila dapat merugikan tanaman secara fisiologis dan secara ekonomis (Asmaliyah dan Darwiati, 2012). Serangga merupakan organisme yang dapat hidup dengan suhu optimal $\pm 26^{\circ} \mathrm{C}$ dan dapat berkembang dengan cepat pada areal tanaman sejenis (monokultur). Pembibitan berbagai jenis tanaman (polikultur) pada areal persemaian menyediakan pakan yang berlimpah bagi serangga dengan di dukung kondisi bibit yang masih muda (tingkat semai) merupakan pakan yang disukai serangga. Hal ini yang menjadi salah satu kendala terpenuhinya pengadaan bibit yang sehat dan berkualitas. Oleh karena itu kegiatan pengendalian hama sangat penting dilakukan untuk mendukung keberhasilan pembangunan

Penelitian ini bertujuan untuk mengidentifikasi serangga hama yang menyerang bibit trembesi di areal persemaian permanen BPDASHL Kapuas Kota Pontianak dan menentukan tingkat kerusakan yang disebabkan oleh serangga hama yang menyerang bibit trembesi. Manfaatnya adalah untuk memberikan informasi jenis serangga hama perusak dan 
memberikan informasi dasar mengenai tindakan yang tepat dalam melakukan pemeliharaan dan perlindungan terhadap bibit trembesi di areal persemaian permanen BPDASHL Kapuas Kota Pontianak.

\section{METODE PENELITIAN}

\section{Tempat dan Waktu Penelitian}

Penelitian ini dilaksanakan di areal persemaian permanen BPDASHL (Balai Pengelolaan Daerah Aliran Sungai dan Hutan Lindung). Pada Oktober 2018 sampai November 2018.
Pelaksanaan penelitain dilakukan dengan metode sensus dengan melakukan observasi langsung di lapangan. Pengambilan data dilakukan dengan melakukan pengamatan terhadap kerusakan bibit trembesi, baik gejala yang muncul pada bibit, serta serangga hama yang di temukan dilapangan. Pengamatan dilakukan pada 4 jalur bibit trembesi dengan total bibit 2.880 bibit, dimana dalam satu jalur terdapat 60 baris dengan jumlah bibit 12 bibit per baris.

Tabel 1. Sampel Bibit Trembesi (Sample of trembesi seedlings)

Jalur jumah total bibit (batang) jumlah baris sampel dari sampel bibit trembesi

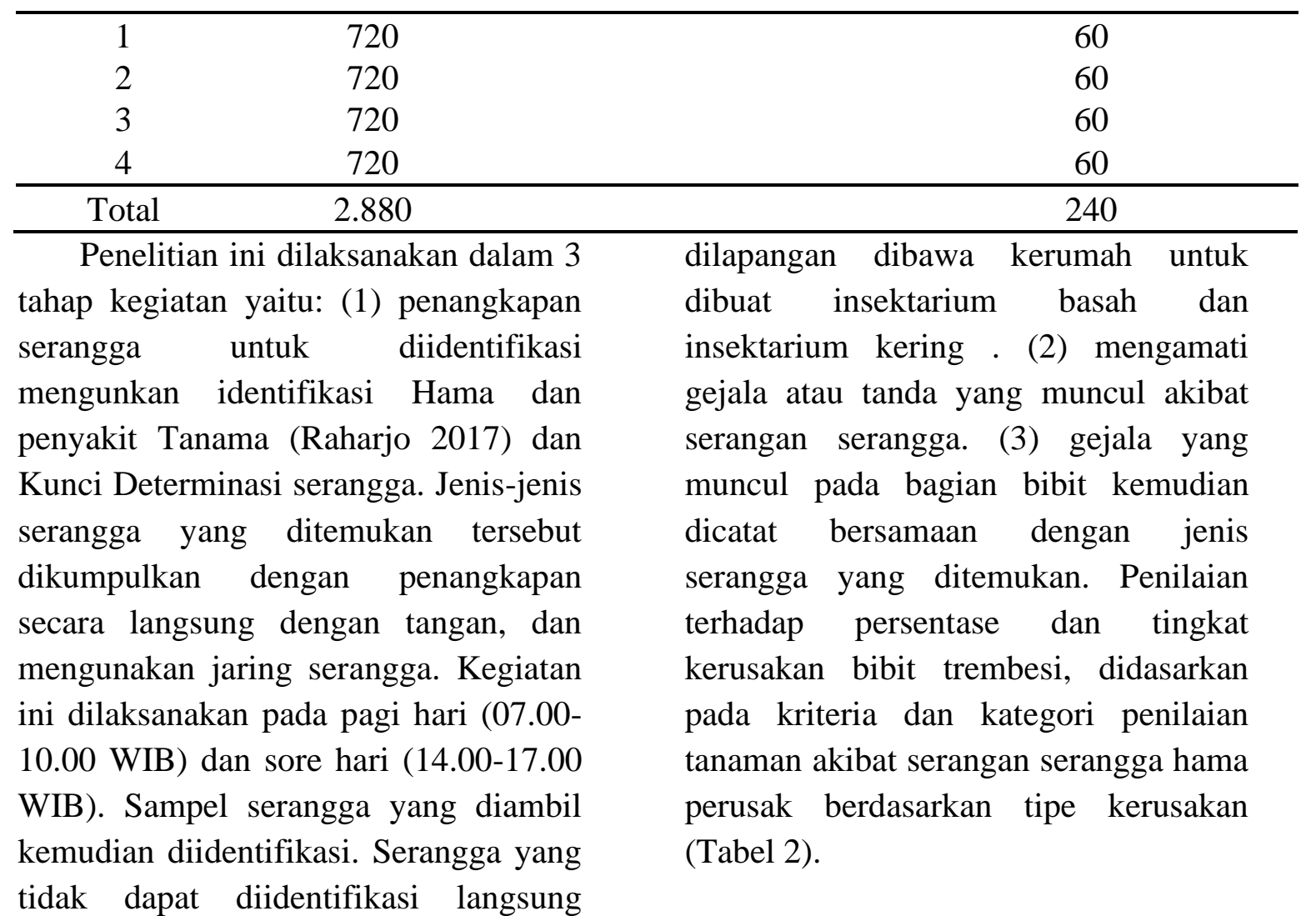


Tabel 2. Kriteria dan kategori penilaian tanaman akibat serangan serangga hama berdasarkan tipe kerusakan yang tampak (Criteria and category of corp evaluation due to pest insect attack based on the type of damage seen)

\begin{tabular}{lll}
\hline Skor & \multicolumn{1}{c}{ Tanda Kerusakan } & \multicolumn{1}{c}{ Kategori } \\
\hline 0 & $\begin{array}{l}\text { Pertumbuhan baik, daun hijau, sehat dan segar, beberapa daun } \\
\text { Hilang dari pangkal batang. }\end{array}$ & Sehat \\
1 & $\begin{array}{l}\text { Bagian tanaman daun berlubang, menggulung, melipat, } \\
\text { Batang berlubang dan mengelupas. 1\%-25\% }\end{array}$ & Ringan \\
2 & $\begin{array}{l}\text { Daunnya menggulung melipat, menggulung berlubang, dan } \\
\text { Kerusakan tersebut sampai kebagian pucuk, muda digigit } \\
\text { sehingga daun menguning. 25\%-50\% }\end{array}$ & \\
& $\begin{array}{l}\text { Tanaman rusak berat, dimana lebih dari setengah tanaman } \\
\text { patah, gundul, leher akar terpotong, sehingga tumbang hamper } \\
\text { matiTanaman mati atau rusak berat 50\%-100\% }\end{array}$ & \\
\end{tabular}

Sumber : Direktorat Perlindungan Tanaman, (2000)

Jenis-jenis serangga hama yang

telah diambil dari lapangan kemudian

dilakukan identifikasi dengan pedoman

buku kunci pengenalan serangga.

Analisis data dilakukan menggunakan rumus sebagai berikut.

1. Perhitungan persentase tanaman terserang tiap-tiap jalur

$$
\mathrm{P}=\frac{\alpha}{N} \times 100 \%
$$

Keterangan :

$\mathrm{P}=$ persentase tanaman terserang

$\alpha=$ Jumlah tanaman yang terserang

$\mathrm{N}=$ jumlah tanaman yang diamati

2. Tingkat kerusakan pada tiap jalur pengamatan

$\mathrm{I}=\frac{\sum(n i x V i)}{Z N} x 100 \%$

Keterangan:

$\mathrm{I}=$ Tingkat kerusakan pada setiap jalur

$\mathrm{N}=$ Jumlah tanaman pada setiap jalur ni $=$ Jumlah tanaman berdasarkan

kriteria serangan

$\mathrm{Vi}=$ Nilai kriteria untuk serangan hama

$\mathrm{Z}=$ Nilai tertinggi kriteria serangan

hama

3. Tingkat kerusakan seluruh jalur pengamatan

$\mathrm{Y}=\frac{\sum I}{N}$

Keterangan:

$\mathrm{Y}=$ Tingkat kerusakan seluruh

$\mathrm{I}=$ Tingkat kerusakan tiap jalur

$\mathrm{N}=$ Jumlah jalur.

HASIL DAN PEMBAHASAAN

1. Jenis-Jenis Serangga Hama Perusak Pada Bibit Trembesi

Hasil identifikasi jenis serangga yang ditemukan saat pengamatan langsung dilapangan di dapat 5 jenis serangga yang menyebabkan kerusakan pada bibit trembesi dapat dilihat pada Tabel 3. 
Tabel 3. Jenis-jenis Serangga Yang Merusak Tanaman Trembesi diareal Persemaian (A types of pest insects that damage trembesi plants in the nursery area).

\begin{tabular}{|c|c|c|c|c|c|c|}
\hline No. & Ordo & Famili & Species & $\begin{array}{l}\text { Nama } \\
\text { Daerah }\end{array}$ & $\begin{array}{c}\text { Stadium } \\
\text { Serangga } \\
\text { Perusak } \\
\end{array}$ & $\begin{array}{c}\text { Bagian } \\
\text { Yang } \\
\text { Diserang } \\
\end{array}$ \\
\hline \multirow{3}{*}{1} & \multirow{3}{*}{ Orthoptera } & Tettigudine & $\begin{array}{c}\text { Tagasta } \\
\text { marginella }\end{array}$ & $\begin{array}{l}\text { Belalang } \\
\text { Kerucut }\end{array}$ & Dewasa & Daun \\
\hline & & Arcididae & Oxya sp. & $\begin{array}{c}\text { Belalang } \\
\text { Kecil }\end{array}$ & Dewasa & Daun \\
\hline & & Arcididae & $\begin{array}{c}\text { Valanga } \\
\text { nigricornis }\end{array}$ & $\begin{array}{c}\text { Belalang } \\
\text { Kayu }\end{array}$ & Dewasa & Daun \\
\hline 2 & Hemiptera & Coreidae & $\begin{array}{l}\text { Leptocorisa } \\
\text { acuta }\end{array}$ & $\begin{array}{l}\text { Walang } \\
\text { Sangit }\end{array}$ & Dewasa & $\begin{array}{c}\text { Daun } \\
\text { dan } \\
\text { Batang }\end{array}$ \\
\hline 3 & Lepidoptera & Plutellidae & Plutella sp. & $\begin{array}{l}\text { Ulat } \\
\text { Tritip }\end{array}$ & $\begin{array}{c}\text { Larva / } \\
\text { Ulat }\end{array}$ & Daun \\
\hline
\end{tabular}

Tabel 3 menunjukan jenis-jenis serangga hama yang menyebabakan kerusakan pada bibit trembesi diareal BPDASHL Kapuas Kota Pontianak. serangga yang menyerang bibit trembesi.

Belalang kerucut (Tagasta marginella) termasuk famili tettigudine, ordo Orthoptera. memiliki tubuh yang panjang, kepala berbentuk runcing dan alat penelurnya panjang, berwarna hijau dengan bias merah dan memiliki sungut yang runcing seperti kerucut. Belalang kerucut ditemukan pada pagi dan sore hari, ditemukan pada hari setiap petak pengamatan di areal yang terbuka. Kerusakakn akibat belalang kerucut menyebabkan bagian daun mahoni berlubang karena bekas gigitan.

Belalang kecil (Oxya sp) merupakan famili dari Arcididae, ordo orthoptera hasil pengamatan di lapangan di temukan belalang ini dengan ciri-ciri morfologi yaitu memiliki kepala berbetuk kotak Panjang tubuh 3,6 cm warna tubuh cokelat dan kehijauan. Memiliki dua pasang sayap, Belalang ini memiliki 3 pasang kaki, mata majemuk, dan 2 pasang antena berwarna hijau pendek. Kaki bagian belakang panjang dan membesar di gunakan untuk melompat jauh dan tinggi, sedangkan kaki bagian depan pendek yang di gunakan untuk berjalan. Belalang ini di temukan pada pagi hari terbang dan hinggap memakan daun bibit trembesi.

Belalang kayu (Valanga nigricornis) termasuk ordo Orthoptera famili Arcididae dan genus valanga. Pada saat pengamatan di lapangan di temukan dengan ciri morfologi berwarna hitam kecoklatan dengan sedikit bias putih dengan panjang tubuh $4 \mathrm{~cm}$, pada paha belakang terdapat bercak-bercak, tulang betis belakang berwarna hitam dan bercak putih, alat tambahan antara lain dua buah (sepasang) mata facet, sepasang antena, tarsis beruas tiga buah, fermur kaki depan membesar, dan ovositur pendek. Belalang kayu di temukan setiap hari pengamatan dan aktif pada pagi hari. Kerusakan akibat belalang kayu menyebabkan daun dan pucuk bibit 
trembesi robek, berlubang dan tangkai daun ada yang terpotong.

Walang sangit (Leptocorisca acuta) termasuk ordo Hemiptera famili Coreidae dan genus Leptocorisca. Pada saat pengamatan di lapangan walang sangit di temukan dengan ciri morfologi terdiri dari 3 bagian utama yaitu kepala dada dan perut, panjang tubuh $3,2 \mathrm{~cm}$ seluruh tubuhnya berwarna kecoklatan. Walang sangit ini memiliki 3 pasang kaki, 2 belalai panjang yang di gunak untuk mengisap daun dan bakal buah, memiliki 2 pasang mata dengan tipe mata majemuk tipe alat mulut mengigit mengunyah. Kaki bagian belakang panjang dan membesar yang di gunakan untuk meloncata jauh. Kaki bagian depan pendek yang di gunakan untuk berjalan. Walang sangit di temukan pada pagi hari terbang hinggap dan memakan daun bibit trembesi.

Ulat tritip (plutella sp) hasil pengamatan di lapangan di temukan ulat tritip dengan ciri tubuh berwarna hijau muda dengan panjang $1,8 \mathrm{~cm}$ yang tersusun atas 11 ruas, tipe alat mulut mengigit mengunyah. Pada saat pengamatan ulat ini banyak di temukan di tepi daun gulunggan daun ulat tritip memakan semua daun mudan ranting dan batang dengan bekas gigitan seperti bekas gergaji yang terdapat di pinggir daun dan berlobang. Hasil yang di peroleh sama dengan pendapat (Anggraeni dan Ismanto, 2013) Yang menyatakan pada ulat tririp memiliki ciri warna tubuh berwarna hijau dengan tipe mulut mengigit dan mengunyah dan pada saat merasa terancam ulat ini segera menjatuhkan diri. Pada saat pengamatan ulat tritip di temukan pada pagi hari dan jenis ulat ini sanggat mendominasi memakan daun bibit trembesi dan hampir di jumpai setiap pagi hari setiap pengamatan. Hasil pengamatam dilapangan kategori kerusakan tanaman pada bibit trembesi yang terserang hama terlihat pada Gambar 1. 


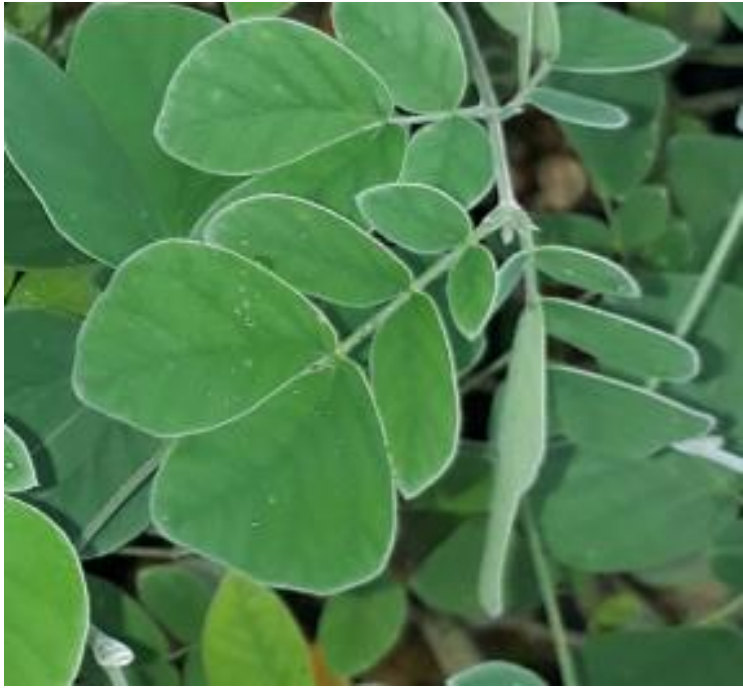

(a)

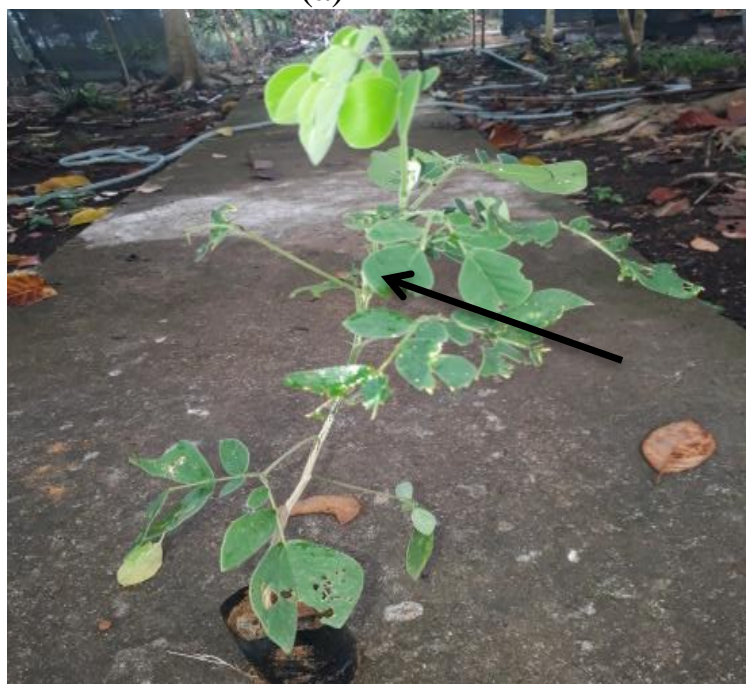

(c)

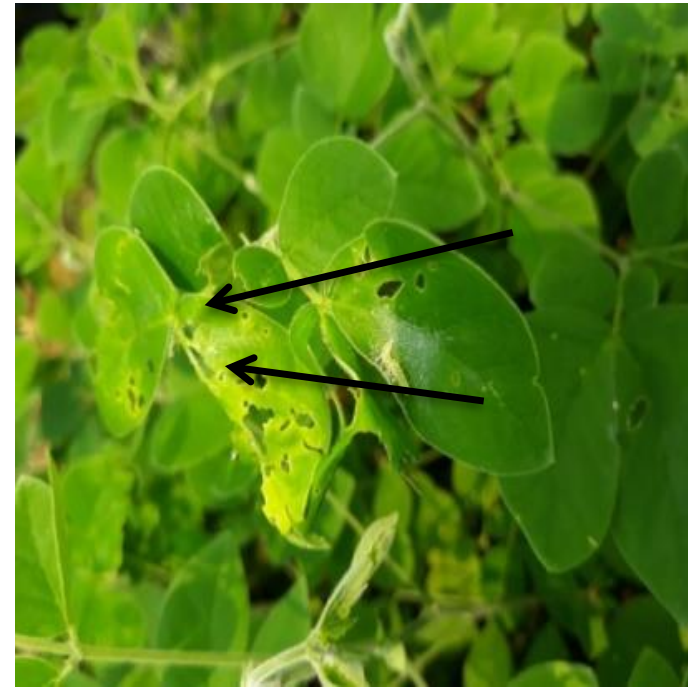

(b)

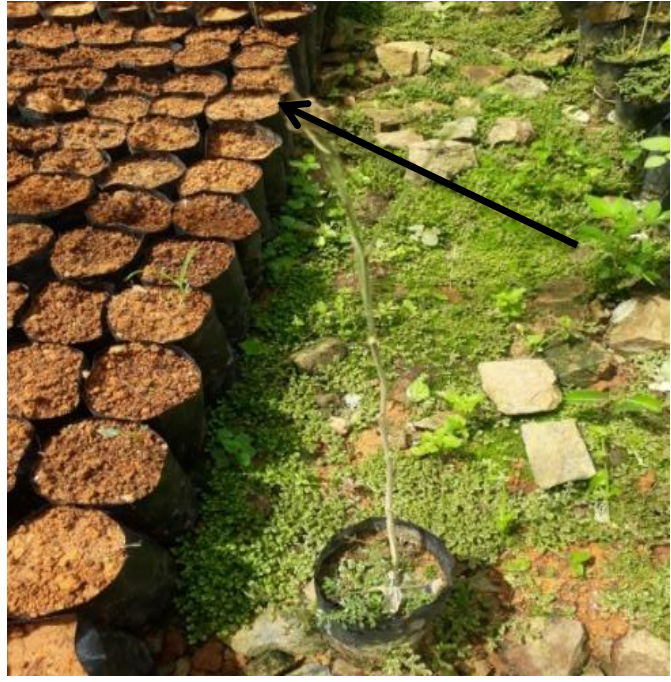

(d)

Gambar 1. Kategori kerusakan daun bibit trembesi yang terserang serangga hama (a). sehat (daun hijau, sehat dan segar) (b). Kerusakan ringan (bagian tepi daun rusak sebagain) (c). kerusakan (daunnya mengulung berlipat dan berlubang) (d). Kerusakan berat (tanaman rusak berat, dimana lebih dari setengah tanaman patah, gundul).

(Category of damage to trembesi seedling leaves which are attacked by pest insects (a). healthy (green leaves, healthy and fresh) (b). Minor damage (part of leaf edge is damaged) (c). damage (folded and perforated leaves) (d). Severe damage (severely damaged plants, where more than half the plants are broken, bald).

\section{Persentase Bibit Terserang trembesi di peroleh tingkat kerusakan serangga hama \\ Hasil pengamatan di lapangan yang dan Persentase bibit yang terserang akibat serangan serangga hama perusak.} diamati pada 4 jalur pengamatan bibit 
Tabel 4. Jumlah Bibit Trembesi yang Rusak dan Persentsae Kerusakan Akibat Serangan Serangga Hama (Number of damaged trembesi seedlings and percentage of damage due to insect pests).

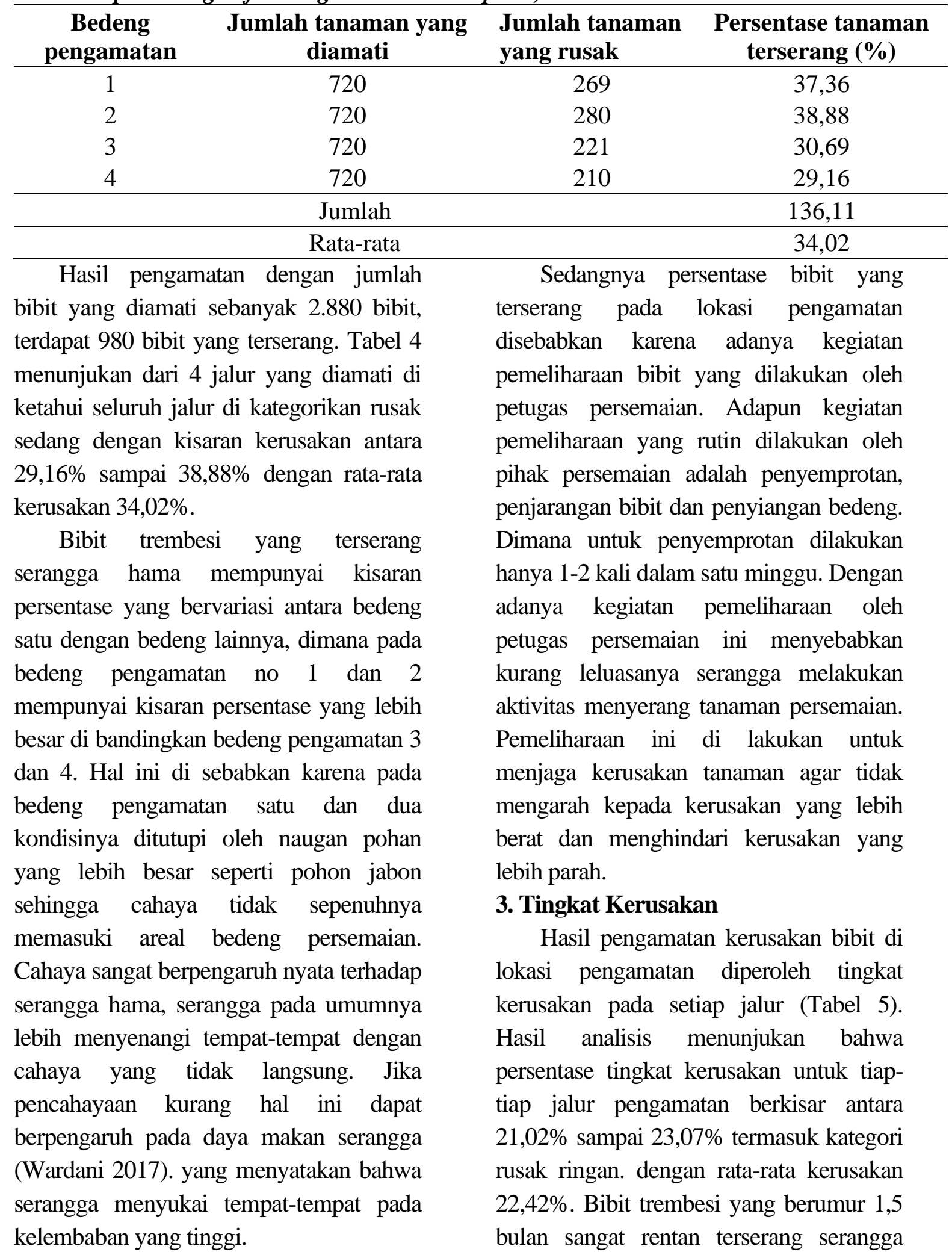


perusak, ketersediaan makanan secara

populasi serangga hama perusak.

berkelanjutan berpengaruh terhadap

Tabel 5. Jumlah Bibit Trembesi Yang Rusak dan Tingkat Kerusakan Akibat Serangan Serangga Hama (The number of damaged trembesi seedlings and the level of damage caused by insect pests)

\begin{tabular}{|c|c|c|c|}
\hline $\begin{array}{c}\text { Bedeng } \\
\text { pengamatan }\end{array}$ & $\begin{array}{c}\text { Jumlah tanaman } \\
\text { yang diamati }\end{array}$ & $\begin{array}{c}\text { Tingkat } \\
\text { kerusakan } \\
(\%)\end{array}$ & Kategori tingkat kerusakan \\
\hline 1 & 720 & 21,02 & Ringan \\
\hline 2 & 720 & 22,87 & Ringan \\
\hline 3 & 720 & 22,73 & Ringan \\
\hline 4 & 720 & 23,07 & Ringan \\
\hline \multicolumn{2}{|c|}{ Jumlah } & 89,69 & \\
\hline \multicolumn{2}{|c|}{ Rata-rata } & 22,42 & Ringan \\
\hline
\end{tabular}

Faktor yang menyebabkan ringanya kerusakan bibit yang terjadi adalah karena kegiataan pemeliharaan bibit yang di lakukan oleh petugas persemaian seperti penyemprotan, penjarangan bibit dan penyiangan bedeng. Pemeliharaan ini dilakukan untuk menghindari kerusakan yang lebih berat dan juga mengurangi populasi serangga hama dimana menurut Roshetko et al. (2015) bahwa ketersediaan makanan secara berkelanjutan sangatlah mempengaruhi besarnya populasi hama.

Faktor lain yang menyebabkan ringannya kerusakan yang terjadi pada tanaman di persemaian adalah adanya saingan makanan di mana di sekitar lokasi persemaian banyak di tanam poho-pohon berdaun lebar hal ini dapat mengalih perhatian makanan bagi serangga hama, sehingga serangga hama tidak hanya makan tanaman di areal persemaian saja tetapi juga berbagi dengan tanaman yang ada di sekitar persemaian.
Walaupun kerusakan yang terjadi digolongkan kedalam kategori ringan tetapi perlu diantisipasi sehingga kerusakannya tidak meningkat yang mengarah kepada kategori berat ( Flint dan Bosch, 1990). Untuk itu perlu adanya tindakan pencegahan dengan cara sistem silvikultur yaitu pengaturan jarak letak bibit, pemeliharaan bibit, penyiangan dan penyemprotan.

\section{Kesimpulan}

Hasil pengamatan menyatakan terdapat 5 jenis serangga hama yang merusak bibit trembesi (Samanea saman), Belalang kerucut (Tagasta marginella), Belalang kecil (Oxya sp.), belalang kayu (Valanga nigricornis), walang sangit (Leptocorisa acuta), Ulat tritip (Plutella sp.). Persentase bibit terserang oleh serangga hama di areal persemaian permanen BPDASHL Kapuas Kota pontianak dengan umur bibit 1,5 bulan adalah $34,02 \%$ termasuk kedalam kategori sedang. Tingkat kerusakan bibit terserang oleh serangga hama perusak bibit trembesi di areal persemaian permanen BPDASHL 
Kapuas Kota Pontianak dengan umur bibit 1,5 bulan adalah 22,42 dari total bibit sebanyak 2.880 bibit yang diamati dan termasuk ke dalam kategori rusak ringan. Cara mengurangi serangan serangga hama yang merusak bibit trembesi yaitu perlu ditingkatkan pembersihan lingkungan di sekitar areal secara teratur dan baik agar dapat mengurangi besarnya potensi persentase dan tingkat kerusakan bibit trembesi. Manajemen sumber daya manusia agar lebih memaksimalkan pemeliharaan terhadap bibit dan lingkungan sekitar.

\section{DAFTAR PUSTAKA}

Asmaliyah A. I. dan Darwiati W. 2012. Identifikasi dan Potensi Kerusakan Rayap Pada tanaman tembesu di kebun percobaan way Hanakau, Lampung Utara. Jurnal Penelitian Hutan Tanaman Industri. 10 (1) : 187-194.

Anggraeni I, Ismanto A. 2013. Kenaekaragaman ulat kantong yang menyerang di berbagai pertanaman sengon (Paraserianthes falcataria (L). Nielsen) Di Pulau Jawa. Jurnal Sains Natural. 15 (1) : 25-40.

Direktorat Perlindungan Tanaman Pangan. 2000. Laporan Luas dan Serangan Hama dan Penyakit Tanaman Pangan di Indonesia. Jakarta: Direktorat Perlindungan Tanaman Pangan.

Flint, M L. dan RD. Bosch 1990. Pengendalian Hama Terpadu, Sebuah Pengantar. Tesis. Bogor: IPB
Krisnawati H, Varis E, Kallio M, Markku K. 2011. Paraserianthes falcararia (L) Nielsen Ekologi, Silvikultur dan Produktivitas. Bogor: CIFOR.

Mursono. 2015. Peningkatan Produktifitas dalam Pembangunan Hutan Alam Berkelanjutan. Pidato Pengukuhan Jabatan Guru Besar dalam Ekologi Hutan pada Fakultas Kehutanan. Yogyakarta: Universitas Gadjah Mada.

Raharjo, 2017. Pengolongaan Hama, Penyakit, dan Gulma dalam Pembangunan Hutan Tanaman Industri dan Usaha Pembangunannya http: //library.usu.ac.id. (Diakses tanggal 13 Oktober 2009).

Roshetko JM, Sebastian GE, Tolentino, $\mathrm{Jr}$ El, Carandang WM, Bertomeu M, Tabdaba A,Yao CE. 2015. Buku Acuan Pembibitan Pohon. Bogor: World Agroforestry Centre.

Prakoso. 2017. Studi jenis serangga dan tingkat kerusakan tengkawang (Shorea), di areal persemaian CV. Bangun Mitra Sehati Kecamatan Sanggau Ledo Kabupaten Bengkayang: Jurnal Hutan Lestari. 5 (4) : 20-35.

Wardani N. 2017. Perubahan Iklim dan Pengaruhnya Terhadap Serangga Hama. Prosiding Seminar Nasional Agroinovasi Spesifik Lokasi Untuk Ketahanan Pangan pada Era Masyarakat Ekonomi ASEAN. Lampung: Balai Pengkajian Teknologi Pertanian. 